\title{
TRIOUSPID STENOSIS, WITH REPORT OF A CURE.
}

\author{
W. IV. HERRICK, M.D. \\ NEW YORK CITY.
}

Among the hundred and eighty-seven cases of tricuspid stenosis found in the literature in but ten cases was a correct diagnosis made clinically. In view of this fact it seems worth while to record such a case in which the clinical diagnosis was confirmed at autopsy.

Paticnt.-A housewife. aged 35.

History-The patient's father died of leart disease. The patient had measles, mumps, pertussis, scarlatina, diphtheria twice, and smallpox, all in ehildhood; at 10 and 27 acute articular rheumatism, involving knees, ankies and wrists.

Onset of Present Illness.-The patient was first admitted to St. Inke's Hospital, April 20, 1905, giving history of shortness of breath, palpitation and observed irregularity of heart during the past four years. Three years before admission the abdomen began to swell and was first tapped one year later. Tapping mas repeated four months, and again six wecks before entering the hospital. The only complaint throughout this period was shortness of breath "when the ab. domen was swollen."

First Physical Examination (April, 1905).-Heart: Apex in fifth space, $41 / 2$ inches to the left of mid-sternum. Right border $2 \frac{1}{2}$ inches from midsternum in third space. Action regular. First apical sound loud; second pulmonic. not accentuated. Second aortic inaudible. At mitral area, and, transmitted to the left, a blowing systolic murmur. At aortic area a pronounced systolic thrill and a double murmur, a systolic, loud and harsh in quality, transmitted upward and heard in vessels of neck, also over greater part of anterior chest. and, posteriorly, between scapulx; a blowing diastolic transmitted down left border of sternum.

Pulse: Small, regular, moderate force. Veins of neck distended; pulsation not remarked. Srstolic arterial pressure $120 \mathrm{~mm}$.

Chest: Small fluid accumulation at both bases.

Abdomen: Enormously distended, signs being those of large amount of fluid.

Extremities: Edematous, indurated, pigmented; superficial veins dilated.

Following aspiration of 592 ounces of flud from peritoneal cavity, friction fremitus was noted over liver, edge of which was palpable three inches below costal border.

Remission.-Improvement was rapid; the patient left the hospital and was not heard from until over two rears later. In August, 1907 , she was readmitted complaining of edema, dyspnea and weakness.

Second Physical Fxamination (August, 1907).-Heart: Apex in fifth space, $4 \frac{1}{2}$ inches to left of mid-sternum. Action irregular, intermittent, poor force. At apex a rumbling presystolic murmur and blowing systolic murmur, a loud first sound. At aortic area a double murmur, a systolic of rough, intense quality transmitted upward, heard in vessels of neck and a diastolic referred down sternum and also heard in sccond and third left interspaces. In fourth and fifth spaces to right of sternum a soft, blowing systolic of very different quality from 
apical murmur of same phase, and a snapping, valvular second sound. Right border 2 inches from mid-sternum in third interspace. Epigastric pulsation marked. Veins of neck widely distended, but without visible pulsation.

Pulse: Irregular, small, of poor force; tension $105 \mathrm{~mm}$.

Moderate effusion in right pleural space.

Aldomen: Circumference 62 inches, symmetrical, tense, showing distinct signs of fluid.

Extremities: Markedly elematous, exeoriated, ulcerating.

Chinical Courss.- Rest in bel, abdominal paracentesis, digitalis and morphin, as the only therapeutic measures, enabled the patient to sit in a chair after twelve days and she was soon walking about the ward. In the interval from August 26 to November 16 , the abdomen was tapped eleven times and a total of 3,665 ounces of fluid removet. There was constant diffuse cyanosis of the entire body, but slight edema of the extremities after the first week, and little or no Jyspnea, except when the abdomen became greatly distended with fluid. Leaving the hospital Yorember. 1907, the patient continued in comfort mil Itarch, 1908, when ascites compelled her return. The cardiac signs were the same as previously, except that a diastolic murmur of quality thought to be different from that heard at the aortic area was noted at the ensiform.

Diagnosis._Aortic stenosis and insufficiency with mitral insufficiency had bcen the most frequent diagnosis during the patient's stay in the hospital. The presence of a tricuspid stenosis suggested itself to me in 1907, and was affirmed positively and independently by Dr. Van Horne Norrie, on whose service the patient came to autopsy, and by whose courtesy I am able to publish this report.

Autopsy.-The patient died April 30, 1908. The autopsy, by Dr. Zinsser, showed:

Heart: Apex in seventh space, 41/2 inches to left of mid-sternum. Right border $3 / 4$ inch to right of right sternal margin. Pericardial sac totally obliterated by very firm adhesive periearditis. Right anriele and rentricle much dilated, walls flabby and thin. Tricuspid valve scgments much thickened, adherent at angles. forming a firm ring abont auriculoventricular opening. which admited with difficulty tips of two fingers, and forming distinct stenosis. Pulmonary valves normil. Jeft ventriele greatly hypertrophied showing interstitial myocarditis. Aortic valve adherent; marked thickening of valve segments with resultant button hole stenosis, Mitral ralve with funnel stenosis admitting one finger. To fresh regetations on endocardium.

Icft pleural cavity: Large amount of fluid. Left lung thickened, atelectatic, compressed to one-fifth normal volume.

Riglit lung: With adhesive pleurisy of long standing.

Abdomen: Peritoneum universally thickened, in areas showing fibrinous exudate.

Liver: Weight, 2,890 gm., marked perihepatitis (Zuckergussleber), chronic congestion, cirrhosis of pronounced degree.

Splcen: Very large, marked perisplenitis.

Kidneys: Large, soft, congested.

To become convinced that tricuspid stenosis is not a rare lesion one las to review the obscrvations of the many who have described the condition since Duroziez, in 1868, first bronght it convincingly to notice. The subjective and objective eridences of the condition have been in the rourse of time formulated until a fairy definite clinical picture may be drawn. This has been woll done by T. B. Herrick. 
The case reported well illustrates the important features of the condition: A woman having a history of acute articular rheumatism or chorea, prominent among whose symptoms are persistent cyanosis of mucous meml)ranes and skin, marked tendency to edema or general anasarea and with relatirely little dyspnea; the signs of a mitral stenosis without accentuation of the second pulmonic sound, often, in addition, an aortic lesion, an enlarged right ventricle and auricle, distended veins of the neck, frcquently without pulsation. These comprise the most constant diagnostic factors. To them may be added Mackenzie's observation that seren of these cases proved at autopsy showed a liver pulse of the auricular type. The murmur is very inconstant and more often absent than present. In fact, rery few of the cases carefully obscrved and recorded have shown the presystolic murmur to the right of the sternum so insisted on by many. As a positive sign such a murmur is confirmatory, but negatively has no weight in the diagnosis. All auscultatory signs are so often obscured by the presence of lesion of the mitral and perhaps aortic valves that very great weight can not safely be placed on them.

The remarkable comfort of these patients in the presence of cyanosis and, frequently, edema or general anasarca, has been very often noted. 'This is doubtless due to the effect of the narrowed right auriculorentricular orifice lessening the engorgement of the pulmonary circulation and the consequent dyspnea. This same factor, by its tendency to equalize pressure on either side of the pulmonary valve, furnishes a satisfactory cxplanation for the frequent absence of accentuation of the second pulmonic sound in the presence of the almost universally accompanying stenosis of the mitral valve.

In Stecle's collection of reports of eighty-six cases a chronic obliterating pericarditis was present in seren. Broadbent, Tassen Beck, Cochs and Chadbourne also record one each. These, together with the case here reported, make a total of twelve showing this condition.

Duroziez in 1868, Leudet in 1888 and $\mathrm{J}$. B. Herrick in 1897 have summarized the cases of tricuspid stenosis, the last-named tabulating one hundred and fifty-four. In reviewing subsequent literature I have found reports, complete or incomplete, of thirty-three additional cases. These include eight collected by Sattcrthwaite in 1902. 
SLMANARY OF REPORTED CASES TO DATE

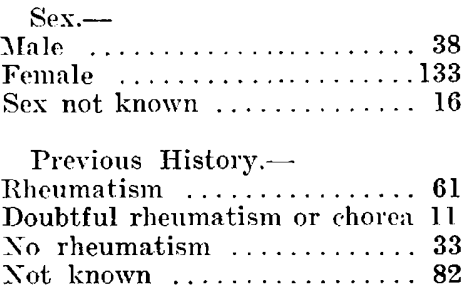

Age.-

10 to 20 years........... 16

20 to 30 years........... 59

30 to 40 vears........... 38

40 to 50 years........... 28

50 to 60 years........... 10

60 to 70 years.......... 6

Not known ............. 30

No rheumatism .......... 33

Not known .............. 82

Total cases ..........187

Association of Valvular Lesions.-

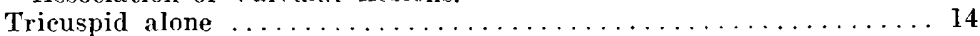

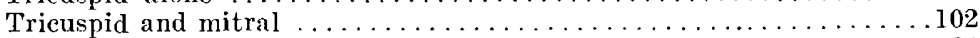

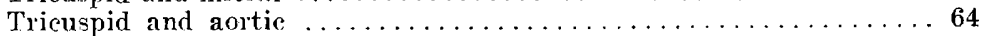

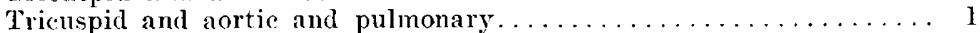

Tricuspid and endocardium of left auricle $\ldots \ldots \ldots \ldots \ldots \ldots \ldots$

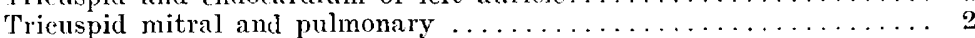

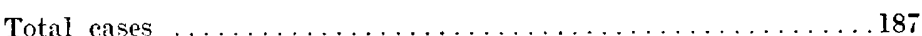

Cases showing adherent pericardium $\ldots \ldots \ldots \ldots \ldots \ldots \ldots \ldots \ldots \ldots$

BHBLIOGRA PHY

Duroziez: Gaz. d. hôp.. 1868, xli, 310.

Leudet: Thèse de Paris, 1888.

Herrick, J. B.: Boston Med. and Surg. Jour., 1897, exxxvi, 245.

Satterthwaite: Med. News, New York, 1902, lxxxi, 449.

Griflith: Edinburg Med. Jour.. 1903, xiii. 112.

Barjon and Thenet: Tỵon méd., 1906, avii, 112.

Hitz: Arch. gén. de méd., 1906, i, 14.

Croom: Edinburgh Med. Jomr., 1905. xviii, 231-237.

Cocks: Post-Graduate, 1906, xxi, 343.

Gibson: Tr. Med. Chir. Soc., Ed̉inburgh, 1905, xxiv, 195.

Cohn, Ernst: Ein Fall von Tricuspidalstenose ...., Leipsic, 1883.

Post, J.: Ueber Tricuspidalstenose, Wiirzburg, 1891.

Fenwick: Tr. Path. Soc., London, 1881, xxxii, 42.

Chadbourne: Am. Jour. Med. Se, 1900, exix, 306.

Markenzic: The Study of the Pulse and Movements of the Heart, p. 191.

Steele: Philadelphia Path. Sor. Rep., 1896, ix, 200. 